\title{
Russia invests in a 'revolutionary' disc
}

[MOscow] A Russian-born physicist who emigrated from the Soviet Union in 1975 has persuaded the government to invest in a factory to make what he claims is a "revolutionary" three-dimensional compact disc, able to store information at up to 50 separate levels.

Eugene Levich has recruited Egor Stroev, speaker of the Federation Council - the upper chamber of the Russian parliament as chairman of the company, 3-DOM, set up to produce the discs. When Levich left the Soviet Union in the 1970s he went with his father, Veniamin Levich, a corresponding member of the Academy of Sciences.

Sergey Shcheblygin, one of Stroev's advisers, confirms that the Russian government has deposited money in an account, confirming its intention to participate in the project. Shcheblygin says 3-DOM is not entitled to spend the money, but Levich insists the company can use it as it wishes, a view supported by fellow director Iosif Diskin, deputy director of the population institute of the Russian Academy of Sciences.

3-DOM will make multilayer fluorescent discs (MFDs), which it claims can store tens or hundreds of times more information than standard discs, but at the same price. According to Diskin, the design of the discs is based on so-called 'stable photochrome', discovered by physicists and engineers who emigrated from the former Soviet Union.

This is a transparent organic substance which fluoresces when subject to a laser beam for sufficient time to be detected by a standard photo-receiver. This characteristic makes it possible to superimpose up to 50 transparent layers on top of one another, and to 'write' information on each level, which can be read either in succession or in parallel.

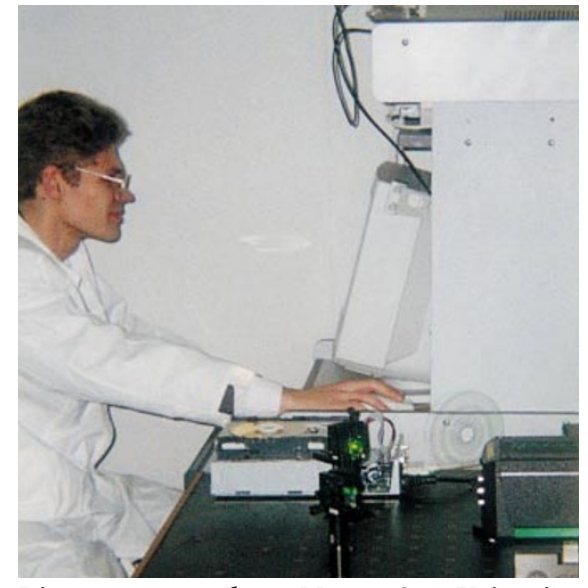

Disc man: a researcher at Moscow State University Science Park with the 3D compact disc (right).

The science has been known about for some time in the West, and is said to have been investigated by companies such as IBM and Philips, but the reading-devices needed are so complex that none has made any public commitment to invest in the technology.

"The scientific aspects are sound, but it is still untried as a technology," says Nicolaas Bloembergen of Harvard University, 1981 Nobel prize-winner in physics, who has been recruited to 3-DOM's scientific advisory board. "It appears to work in a laboratory demonstration. The big question is whether it is worth taking the technological risk."

Diskin says production of the discs is due to start in Russia by next summer. But Levich admits that so far all MFDs have been made by hand, and that a production line has still to be designed. Both have told Shcheblygin that specifications are being drawn up for equipment to be installed in the former Control electronic machines factory in Orel, but decline to provide further details.

\section{India urged to act against leptospirosis}

[NEW DELHI] Medical researchers in India have urged the government to take prompt action to prevent leptospirosis from becoming a major public health problem following several outbreaks of the disease, which is spread mostly by rats.

Last year, 90 people died in four outbreaks, including one in a medical college hostel in Mysore whose drinking water was contaminated with rat urine. Health officials fear it may be impossible to control the disease unless an effective rat control strategy is found. Little is known about the identity of other potential animal carriers of leptospirosis.

Officials point out that the disease can be treated with antibiotics such as penicillin. But Vulimiri Ramalingaswami, former chief of the Indian Council of Medical Research, says it is essential to develop tools to detect leptospirosis and to launch a surveillance programme. "Otherwise, India would face a major public health problem in the event of [the disease-causing bacteria] developing resistance to penicillin."

Leptospirosis causes a high temperature and jaundice, and affects the lungs, kidneys and brain. It is caused by a spiral bacterium, Leptospira interrogans. Infected animals shed the bacteria in urine and people coming into contact with contaminated water or soil pick up the infection through the skin and mucous membrane.

Experts told a conference in New Delhi last week that mushrooming slums in cities and the rise in development activity in villages provide ideal environments for the disease to spread.
Diskin says the initial plan is to use MFD for high-definition television, as current DVD discs cannot store sufficient information for a two-hour video. "Our technology is so simple that producing a disc holding a high-definition TV film worth $\$ 100$ costs us practically nothing," he says. He predicts that in one year, when the factory starts production, it could pay taxes comparable to "the whole budget of Orel district".

The financial backing to the project is complex. The Austrian-registered company Constellation Group owns 20 per cent of the share in 3-DOM, as well as the capital of two other companies, the US-based Constellation Memory Division Inc., (which owns 20 per cent of 3-DOM shares) and High Technology Projects (14 per cent). Levich heads the first two companies, and Diskin the third.

The remaining capital is held by the Russian district administration of Orel, of which Stroev is governor (33 per cent); the state property foundation (10 per cent); and Moscow State University ( 3 per cent).

The university's participation is through its Laser Centre, which signed a contract in 1995 with Memory Devices of Maryland, another company created by Levich and Diskin. Under this agreement, the laser centre has developed a two-photon, single beam 'bit-by-bit' writing technique, and a fluorescent 'page-by-page' reading optical data storage system for use with MFDs.

Levich says that the émigré physicists had a choice of offering the technology to the Lawrence Livermore Laboratory in the United States or the International Laser Centre at Moscow State University.

"The fact that two-thirds of Constellation Group are Russians, and that the Russian workforce is less expensive, were not the main reasons we chose Russia," says Levich. "In the United States, people would not listen to our 'crazy' ideas, and kept asking how we had obtained these results while IBM or Sony had failed."

3-DOM's science advisory council is chaired by Viktor Sadovnichy, rector of Moscow State University, and includes prominent scientists such as John Armstrong, formerly chief scientist of IBM, and Mikhail Alfimov, chairman of the Russian foundation for fundamental research.

But Bloembergen says this committee has never met. Promises by Levich that the committee would meet in January, and that samples of the disc would be made available last month, have also failed to materialize. And neither Diskin nor Levich will reveal how to contact the Constellation Group, or any of the companies they have created.

"We are a small group and need to be very cautious surrounded by many powerful rivals," says Levich.

CarlLevitin 